\title{
Correlation of Microalbuminuria and Multiple Risk Factors in Acute Coronary Syndrome
}

\author{
Bhalavi Vaishali ${ }^{1}$, Ghanekar Gayatri ${ }^{2}$
}

\begin{abstract}
Background: The current study was undertaken at tertiary care center, Bhopal, MP, Central India. with the objective is to study the occurrence of microalbuminuria in acute coronary syndrome and to find their association with multiple cardiovascular risk factors. Materials and Methods: The present study was carried out during period jun2009 to 2010 on patients presenting to the cardiology department Hamidia hospital, Bhopal, MP. It was an observational comparison study in which comparison of two groups according to the presence and absence of microalbuminuria in patient diagnosed to have acute coronary syndrome after proper history, thorough clinical examination and investigations and find their correlation with multiple risk factors for acute coronary syndrome. Results and Conclusions: This observation implies that microalbuminuria is significantly more commonly seen in patients with acute coronary syndrome as compared to healthy adults of same biological characteristics. The difference between occurrence of microalbuminuria was significant in cases with multiple risk factors than any isolated single risk factors.
\end{abstract}

Keywords: Microalbuminuria, Multiple risk factors, Acute coronary syndrome

\section{Introduction}

Microalbuminuria (MAU) is a common phenomenon in patients with cardiovascular disease worldwide. Although mortality from coronary heart disease (CHD) has declined since the late 1960s and 1970s in most industrialized countries, CHD is still the leading cause of death. ${ }^{1}$ The geographic and temporal patterns of CHD event rates correspond to trends in the prevalence of classical cardiovascular disease risk factors, with the residual variance in CHD attributable in part to unknown factors ${ }^{2}$. This indicates that non established CHD risk factors might be operational in CHD incidence and mortality and lends support to the continuous search for novel cardiovascular disease risk factors or risk markers that might predict CHD independently of the classical risk factors. Microalbuminuria is one of these possible predictive factors.

Microalbuminuria is associated with an increased risk of cardiovascular and renal disease in patients with diabetes mellitus $^{3,4}$ and hypertension. ${ }^{5,6}$ Although the role microalbuminuria plays in the general population is less well known, studies have shown that it is independently associated with prevalent cardiovascular disease in the general population ${ }^{7,8}$ and that it predicts all-cause and cardiovascular disease mortality in the general population and in nondiabetic persons. ${ }^{9,10,11,12}$ Although the significance of albuminuria as a possible predictor of CHD in persons without diabetes has been suggested, ${ }^{13,14,15}$ there has not been a report from a large population-based cohort study of albuminuria and incident CHD. The prognostic significance of albuminuria in persons with baseline CHD in the general population is also unknown. Therefore, we undertook this study to examine the correlation of microalbuminuria with multiple risk factors in patient with acute coronary syndrome in hamidia hospital Bhopal, MP, Central India.

\section{Materials and Methods}

The present study was carried out during the period of june2009 to september2010 on patients presenting to the cardiology department in Hamidia hospital Bhopal, M.P. It was an observational comparision study, in which intra group comparison was the main focus of analysis.This comparison was done between two groups formed in the study cases by dividing them in two groups according to the presence or absence of microalbuminuria.

Firstly the study population cohort was compared with age and sex matched control population from the same demographic an socioeconomic background for confirming the observation that microalbuminuria was frequent in the study population compared to general population.

All the patients who presented with the history, physical examinations and investigations (ECG, cardiac enzymes) satisfying the criteria for diagnosis of an acute coronary syndrome -including unstable -angina and myocardial infarction were included in the study.

After proper history and thorough clinical examinations data were recorded and other data regarding history of hypertension, diabetes, tobacco use, smoking, past and family history of CAD were noted.

Every patients first morning urine sample on his or her second post admission day was collected and analysed using immunoturbidometric analysis. Microalbuminuria was defined as presence of $30-300 \mathrm{mg} /$ liter of albumin in spot urine sample. Patient received appropriate treatment according to standard protocol and after stabilization patient were subjected to 2-Dechocardiography on day 5.Presence of regional wall motion abnormality, ejection fraction and any other abnormality like pericarditis, apical aneurysm, valvulasr regurgitation and relevant findings were recorded. Subsequently, the patient were followed for the development of any arrhythmias, any conduction defect,left ventricular dysfunction or any other complications or death during their period of hospitalization (average:5days).

The entire data was anlaysed and stastical tests were applied as and when appropriate. 


\section{International Journal of Science and Research (IJSR) \\ ISSN (Online): 2319-7064 \\ Index Copernicus Value (2013): 6.14 | Impact Factor (2014): 5.611}

\section{Inclusion Criteria}

All the patients with history of chest pain and diagnosis consisting of ACS were included in the study regardless of other parameters.

\section{Exclusion Criteria}

1) Those with presence of preexisting renal failure were excluded.

2) Those with stable ischaemic heart diseases were not included.

3) Those with suspected ACS but investigations suggesting alternating diagnosis were excluded.

\section{Results}

Present study included comparision between microalbuminuria positive and negative cases with acute coronary syndrome. There were 55 cases satisfying the criteria for diagnosis of ACS as mentioned earlier and 27 healthy age and sex matched controls. The age group of cases was from 23-90yrs and that of controls was 2884yrs.Microalbuminuria in cases population was found to be in total 34 patients out of 55(61.81\%); whereas in control population, 3 patients comprising of $14.81 \%$.

On comparision of these two populations, the difference between occurrence of microalbuminuria was found to be stastically significant $\left(\mathrm{x}^{2}=11.7\right.$ and $\left.\mathrm{p}<0.05\right)$.(Table:1)

This observation implies that microalbuminuria is significantly more commonly seen in patients with ACS as compared to normal healthy population of same biological characteristics.

The mean age of cases was $52.78+12.96 y$ yrs and $53+10.61$ yrs for controls. The mean age of MA+ve cases was $53.09 \mathrm{yrs}$ and MA-ve cases was51.94 yrs.Maximum number of cases were in $40-49 y r s$ ( $n=17$ or $30.90 \%)$.Maximum number of controls were in 50-59yrs agegroup(n=10 or37.03\%).
Table 1: Shows the characteristics of cases and control in the study.

\begin{tabular}{|c|c|c|c|}
\hline & Cases & Controls & Comments \\
\hline Total Number & 55 & 27 & \\
\hline Males & $47(85.47 \%)$ & $23(85.18 \%)$ & $\mathrm{p}>0.05$ \\
\hline Females & $8(14.54 \%)$ & $4(14.81 \%)$ & $\mathrm{p}>0.05$ \\
\hline Sex Ratio & 5.875 & 5.75 & \\
\hline Mean Age & $52.78+12.96 \mathrm{yrs}$ & $53+10.61 \mathrm{yrs}$ & $\mathrm{p}>0.05$ \\
\hline Total MA+ve(Patients) & $34(61.81 \%)$ & $4(14.81 \%)$ & $\mathrm{P}<0.05$ \\
\hline Total MA+ve(Males) & $28(59.57 \%)$ & $4(100 \%)$ & $\mathrm{P}<0.05$ \\
\hline Total MA-ve(Females) & $6(75 \%)$ & 0 & \\
\hline
\end{tabular}

There were 47(85.45\%) males and 8(14.54\%) females in cases and the sex ratio was 5.875:1.In MA+ve cases,there were $28(82.35 \%)$ males and $6(17.64 \%)$ females and the sex ratio was 4.66:1.In MA-ve cases,there were 19(90.47\%)males and 2(9.52\%) females with the sex ratio of 9.5:1.There were $23(85.18 \%)$ males and $4(14.81 \%)$ females in the control group and the sex ratio was 5.75:1.Table:2 shows variables in genders in the present study.

Table 2: Shows variables in males and females in the present study.

\begin{tabular}{|c|c|c|c|}
\hline & Males & Females & Comments \\
\hline TOTAL CASES & 47 & 8 & \\
\hline MA+VE CASES & 28 & 6 & $\mathrm{p}>0.05$ \\
\hline MA-VE CASES & 19 & 2 & $\mathrm{p}>0.05$ \\
\hline MEAN AGE & $50.55 \pm 11.6 \mathrm{yrs}$ & $65 \pm 13.88 \mathrm{yrs}$ & $\mathrm{p}>0.05$ but $<0.1$ \\
\hline RISK FACTORS & $33(70.21 \%)$ & $4(50 \%)$ & $\mathrm{p}>0.05$ \\
\hline
\end{tabular}

Mean age of males with acute coronary syndrome was $50.55+11.6 y$ rs and that of females with ACS was 65yrs + 13.88yrs. This observation suggests that females with ACS were older than males.Table: 3 shows age distribution of cases of microalbuminuria in the study.Table: 4 and figure 1.shows distribution of the multiple risk factors in cases in the present study.

Table 3: Shows age distribution of cases of microalbuminuria in acute coronary syndrome in the study

\begin{tabular}{|c|c|c|c|}
\hline Age group & Total cases(n=55) & MA+ve(n=34) & MA-ve(n=21) \\
\hline$<50 \mathrm{yrs}$ & $24(43.63 \%)$ & $16(47.05 \%)$ & $8(38.09 \%)$ \\
\hline$>50 \mathrm{yrs}$ & $31(56.36 \%)$ & $18(52.92 \%)$ & $13(61.90 \%)$ \\
\hline
\end{tabular}

Table 4: Shows the distribution of risk factors in cases in the present study

\begin{tabular}{|c|c|c|c|c|c|}
\hline Risk Factors & MA+ve(n=34) & $\begin{array}{c}\text { MA-ve } \\
(\mathrm{n}=21)\end{array}$ & $\begin{array}{c}\text { Total cases } \\
(\mathrm{n}=55)\end{array}$ & $\mathrm{P}$ Value & Significance \\
\hline Diabetes mellitus & $4(11.76 \%)$ & $2(9.52 \%)$ & $6(10.96 \%)$ & $\mathrm{p}>0.05$ & Not significant \\
\hline Hypertension & $3(8.82 \%)$ & $1(4.76 \%)$ & $4(7.27 \%)$ & $\mathrm{p}>0.05$ & Not significant \\
\hline Smoking & $6(17.46 \%)$ & $6(28.57 \%)$ & $12(21.81 \%)$ & $\mathrm{p}>0.05$ & Not significant \\
\hline Multiple risk & $13(38.23 \%)$ & $2(9.52 \%)$ & $15(27.27 \%)$ & $\mathrm{P}<0.05$ & Significant \\
factors & HTN+Smoking=5 & & & & \\
& $\begin{array}{c}\text { DM+Smoking=4 } \\
\text { HTN+DM=3 } \\
\end{array}$ & & & & \\
\hline NO Risk factors & $8(23.52 \%)$ & $10(47.61 \%)$ & $18(32.72 \%)$ & $\mathrm{p}>0.05$ & Not significant \\
\hline
\end{tabular}


International Journal of Science and Research (IJSR)

ISSN (Online): 2319-7064

Index Copernicus Value (2013): 6.14 | Impact Factor (2014): 5.611

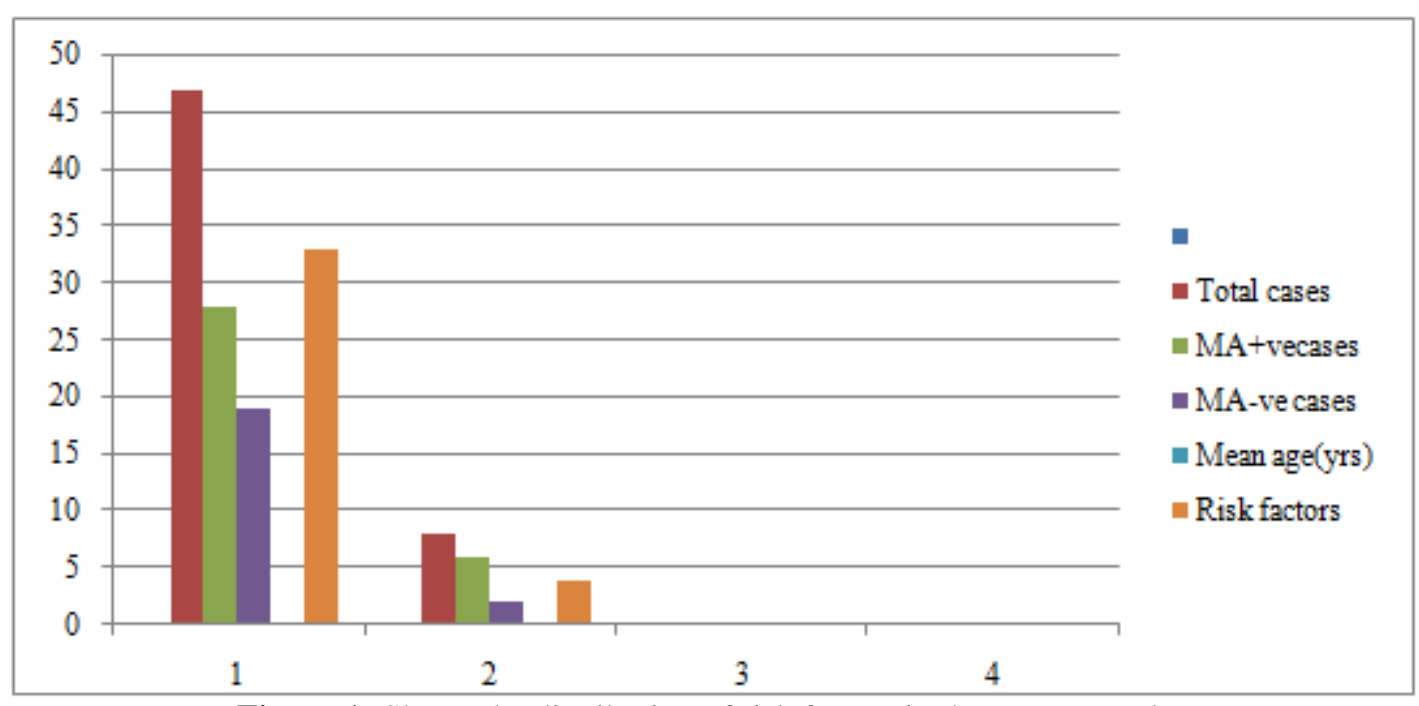

Figure 1: Shows the distribution of risk factors in the present study.

In MA+ve cases, there were 4 cases with DM,3 cases of hypertension ,6 smokers and 13 with multiple risk factors. In MA-ve cases there were 2 cases of DM ,1 case with hypertension and 6 smokers and only 2 with multiple risk factors. The difference between occurrence of microalbuminuria was significant in cases with multiple risk factors than any isolated risk factors.

\section{Discussion}

In our study, mean age of males with acute coronary syndrome was $50.55 \pm 11.6 y r s$ and that of females with ACS was $65 y r s+13.88 y$ yrs similar to the INTERHEART study ${ }^{16}$ where age distribution was mean age of 59+12 for males and women were older than males by $5.4 y$ rs . Various studies from all over world ,including Asia and India, suggest the maximum no of patients with MI or CAD are from the age group of 50-60yrs.Case series study from Iran in 2001,average age of patients was 59.1 $\pm 12.2 \mathrm{yrs}$ and in 1991 this figure was $59.18+10.8 \mathrm{yrs}(\mathrm{p}=0.94)$

In our study females with acute coronary syndrome were older than males similar to INTERHEART study.

Microalbuminuria in females(75\%) was more in our study than males(59.57\%) but this difference was not statiscally significant $(p>0.05)$.This difference may be present due to the fact that females were overall older as compared to males and hence prone to endothelial dysfunction. In PREVEND $^{17}$ study prevalence of microalbuminuria remains fairly constant for females, despite of their age group,but in males prevalence increases after the age of 50yrs.In our study prevalence of microalbuminuria was higher in younger males as compared to older males $(66.66 \%$ in males $<50$ yrs and 52.13 in males $>50 y$ rs of age).

In the present study the difference in occurrence of microalbuminuria were significant $(\mathrm{p}<0.05)$ in acute coronary syndrome with multiple risk factors than isolated factor which is similar to DIABHYCAR ${ }^{18}$ and $\mathrm{HOPE}^{19}$ study. In the review article by Dobre $D$, Nimade $S^{20}$ from neither land mentioned that several large prospective studies say that urinary albumin excretion rate has been shown to predict cardiovascular disease in patient with diabetes, hypertension and seemingly healthy individual.

In our study, prevalence of microalbuminuria was $75 \%$ but the MAGIC ${ }^{21}$ study from Italy conducted to evaluate the prevalence and clinical correlates microalbuminuria in essential hypertension reported a considerably less prevalence of MA in untreated hypertensives and the authors state that "the present study reports a $6.7 \%$ prevalence of microalbuminuria in untreated patients with mild to moderate essential hypertension.

This figure differs from those of several previously published reports indicate a variable but considerably higher prevalence of microalbuminuria. These discrepancies are most likely due to different criteria in patient selection (severity of hypertension, age, race, coexistence of renal diseases and technique used for the detection of microalbuminuria).

Smoking is a recognized cardiovascular risk factor, and it may be also related to MAU

Association of smoking and microalbuminuria has been long known. We found a $50 \%$ prevalence of MA in smokers regardless of the duration of amount. In other studies by $\mathbf{H}$ B.Saffar et. al $^{22}$ and Jaun-Manuel Guizer ${ }^{23}$, MAU was more common in smokers than in non-smokers while study by Charles et al. could not confirm this finding ${ }^{24}$.

We carried out this study on patients who had an acute coronary events, whereas the other researchers have included otherwise healthy population apart from presence of hypertension or diabetes and smoking. Our observation on patients with ACS infact represent the small cohorts of hypertensives and diabetics who actually went on to develop a macrovascular complication like MI and this microalbuminuria was probably one of the culprit of high cardiovascular risk indicators.

\section{Conclusions}

The present study concluded the occurrence of microalbuminuria is significantly more in patients with ACS as compared to the general population. Patients with 


\section{International Journal of Science and Research (IJSR) \\ ISSN (Online): 2319-7064 \\ Index Copernicus Value (2013): 6.14 | Impact Factor (2014): 5.611}

multiple cardiovascular risk factors are more likely to have microalbuminuria rather than patients with isolated risk factors like diabetes, hypertension and smoking.

\section{References}

[1] Rayner M, Petersen S. European cardiovascular disease statistics. British Heart Foundation Health Promotion Research Group. Oxford, United Kingdom: Department of Public Health, University of Oxford, 2000.

[2] Kuulasmaa K, Tunstall-Pedoe H, Dobson A, et al. Estimation of contribution of changes in classic risk factors to trends in coronary-event rates across the WHO MONICA Project populations. Lancet 2000;355:675-87.

[3] Deckert T, Yokoyama H, Mathiesen E, et al. Cohort study of predictive value of urinary albumin excretion for atherosclerotic vascular disease in patients with insulin dependent diabetes. BMJ 1996;312:871-4.

[4] Dinneen SF, Gerstein HC. The association of microalbuminuria and mortality in non-insulindependent diabetes mellitus: a systematic overview of the literature.Arch Intern Med 1997;157:1413-18.

[5] Bigazzi R, Bianchi S, Baldari D, et al. Microalbuminuria predicts cardiovascular events and renal insufficiency in patients with essential hypertension. J Hypertens1998;16:1325-33.

[6] Jensen JS, Feldt Rasmussen B, Strandgaard S, et al. Arterial hypertension, microalbuminuria, and risk of ischemic heart disease. Hypertension 2000;35:898-903.

[7] Yudkin JS, Forrest RD, Jackson CA. Microalbuminuria as predictor of vascular disease in non-diabetic subjects: Islington Diabetes Survey. Lancet 1988;2:530-3.

[8] Jensen JS, Borch Johnsen K, Feldt Rasmussen B, et al. Urinary albumin excretion and history of acute myocardial infarction in a cross-sectional population study of 2,613 individuals. J Cardiovasc Risk 1997;4:121-5.

[9] Damsgaard EM, Froland A, Jorgensen OD, et al. Microalbuminuria as predictor of increased mortality in elderly people. BMJ 1990;300:297-300.

[10] Gerstein HC, Mann JF, Yi Q, et al. Albuminuria and risk of cardiovascular events, death, and heart failure in diabetic and nondiabetic individuals. JAMA2001;286:421-6.

[11]Jager A, Kostense PJ, Ruhe HG, et al. Microalbuminuria and peripheral arterial disease are independent predictors of cardiovascular and all-cause mortality, especially among hypertensive subjects: fiveyear follow-up of the Hoorn Study.Arterioscler Thromb Vasc Biol 1999;19:617-24.

[12] Hillege HL, Fidler V, Diercks GF, et al. Urinary albumin excretion predicts cardiovascular and noncardiovascular mortality in general population. Circulation2002;106:1777-82.

[13] Borch Johnsen K, Feldt Rasmussen B, Strandgaard S, et al. Urinary albumin excretion: an independent predictor of ischemic heart disease. Arterioscler Thromb Vasc Biol 1999;19:1992-7.

[14] Kuusisto J, Mykkanen L, Pyorala K, et al. Hyperinsulinemic microalbuminuria: a new risk indicator for coronary heart disease. Circulation 1995;91:831-7.
[15] Gorgels WJ, van der Graaf Y, Hjemdahl P, et al. Urinary excretions of high molecular weight betathromboglobulin and albumin are independently associated with coronary heart disease in women: a nested case-control study of middle-aged women in the Diagnostisch Onderzoek Mammacarcinoom (DOM) Cohort, Utrecht, Netherlands. Am J Epidemiol 1995;142:1157-64.

[16]Lanas F,Avezum A,Leonelo E,Diaz R,Luna M,Islam S,Yusuf S."Risk factors for acute myocardial infarction in Latin America.The INTERHEART Latin America study" for INTERHEART investigators in Latin America from the Facultad de Medicina,Universidad de la Frontera,Temuco,Chile(F.L.);Instituto Dante Pazzanse de Cardiologia,Paulo S,Brazil(A.A);fundacion Cardiovascular del Oriente Colombiano and Department of population health sciences,University of Wisconsin,Madison(L.E.B.);ECLA coordinating center and instituto cardiovascular de Rosario,Argentina(R.D.);Unidad de Cirugia cardiovascular de Guatemala and Ochsner Clinic foundation,Covingtn,La(M.L.); and population Health Research Institute,Health sciences and McMaster University,

Hamilton,Ontario,Canada(S.I,S.Y.).Circulation.2007;11 5:1067-1074American Heart Association,Inc.

[17] Vaur L ${ }^{1}$, Gueret P, Lievre M, Chabaud S, Passa P; DIABHYCAR Study Group (type 2 DIABetes, Hypertension, CARdiovascular Events and Ramipril) study.Development of congestive heart failure in type 2 diabetic patients with microalbuminuria or proteinuria: observations from the DIABHYCAR (type 2 DIABetes, Hypertension, CArdiovascular Events and Ramipril) study. Diabetes Care. 2003 Mar;26(3):855-60.

[18]Paul E,Jong DE,Hans L,Joan S,Sietsma P and Dick De.Screening for microalbuminuria in the general population:tool to detect subjects at risk for progressive renal failure in an early phase.Deprtment of Medicine,Division of Nephrology and Department of clinical Pharmacology,University hospital Groningen,The Netherland PREVEND study, which was carried out inGroningen,Netherland, to study the impact of microalbuminuria in the general population(Prevention of Renal and Vascular End-stage Disease)Am J Cardiol 2000;86:635-638 Circulation 2004;11:2809-16.

[19]HOPE study(Heart Outcomes Prevention and Evaluation study)N Engl J Med 2000;342:145-153 January 20,2000.

[20]DobreD and Nimade S.Albuminuria in heart failure, what do we really know? From Netherlands.Curr Opin Cardiol.March 2009;24(2)148-154.

[21] Pontremoli R,Sofia A,Ravera M,Nicolella C,Viazzi F,Tirotta A,RuellaN,Tomolillo C, Castello C, Grillo G,Sacchi G, Deferrari G.Prevalence and clinical correlates of microalbuminuria in essential hypertension."The MAGIC study" from department of Internal Medicine (R.P.,A.S.,M.R.,C.N.,F.V.,A.T.,N.R.,C.T.,G.D.,)and the institute of general pathology (G.S.)University of Genoa; and the Division of Medicine, Galliera (C.C.) and Martino S(G.G.)hospital,Genoa, Italy Hypertension.1997;30:1135-1143. 


\section{International Journal of Science and Research (IJSR) \\ ISSN (Online): 2319-7064}

Index Copernicus Value (2013): 6.14 | Impact Factor (2014): 5.611

[22] Hilal Bahjet Al-Saffar, Hussein Nassir, Anna Mitchell, and Sebastian Phillip Microalbuminuria in non-diabetic patients with unstable angina/non ST-segment elevation myocardial infarction. BMC Res Notes. 2015; 8: 371.

[23] Guizer J, Kornhanser C, Malacara J, et al. Renal function reserve in patients with recently diagnosed type 2 diabetes mellitus with and with out microalbuminuria. Nephron. 2001;84:223-230.

[24] Valmadrid CT, Klein R, Moss SE, Klein BE. The risk of cardiovascular disease mortality associated with microalbuminuria and gross proteinuria in person with older-onset diabetes mellitus. Arch Intern med.2000;160(8):1093-1100.

doi: 10.1001/archinte.160.8.1093. 